\title{
LAS PROSIFICACIONES EN JUAN RAMÓN JIMÉNEZ: EL PROYECTO DE LEYENDA
}

\author{
Benigno LEÓN FELIPE \\ Universidad de La Laguna \\ bleon@ull.es
}

Resumen: Este artículo trata de determinar, por un lado, la justificación y coherencia de la decisión de J. R. J. de prosificar toda su poesía versolibrista sin rima, y, por otro, la conveniencia de su plasmación posterior llevada a cabo por A. Sánchez Romeralo en el proyecto de Leyenda.

Abstract: This article intends to determine, on the one hand, the justification and coherence of Juan Ramón Jiménez's decision of prosifying all his free-verse, unrhymed poetry. On the other hand, the convenience of its realization afterwards taken into effect by Antonio Sánchez Romeralo, in his project Leyenda.

Palabras clave: literatura española, poesía en prosa, Juan Ramón Jiménez, siglo XX.

Key words: Spanish literature, prose poetry, Juan Ramón Jiménez, 20th century. 
La idea de prosificar toda su poesía versolibrista sin rima que Juan Ramón Jiménez se propuso hacer, e hizo en parte, requiere, antes de entrar en cualquier otra consideración, determinar si se justifica y es coherente desde su particular concepción de la poesía. En varios lugares dejó expresada con bastante claridad su opinión al respecto. En una carta, fechada en marzo de 1953, dirigida a Díaz-Plaja (1956: 61), encontramos la siguiente afirmación: «El verso se diferencia de la prosa solamente por la rima. No hay prosa «y» verso. Todo es prosa o todo es verso. Para mí, sin duda todo es verso, como para mí todo nuestro movernos es danza». Y en «Poesía cerrada y poesía abierta» (1954) resalta el carácter musical, frente al visual, de la poesía:

Para un ciego el verso y la prosa serían iguales. Y en realidad no existe el verso más que por el consonante y el asonante, por la rima. El ciego es siempre una gran autoridad para la escritura poética. Si no se viese escrita la poesía, iqué distintas serían las opiniones sobre ella! (Páginas escojidas. Prosa, Madrid, Gredos, 1970, p. 193).

De ahí que, según Díaz-Plaja (1956: 63), Juan Ramón pensara reunir todos sus poemas en prosa, unos doscientos cincuenta textos, en un libro que se titularía precisamente Versos para ciegos, que no vería la luz.

En sus Conversaciones con Ricardo Gullón (1958: 114, 115) insiste en las mismas ideas:

No hay prosa y verso (...); lo que les diferencia es la rima. Si no la hay, todo es prosa, y ésta puede recortarse y escribirse en verso. Por eso estoy pensando, para sucesivas ediciones de mis obras, en dar el verso como prosa.(...)

La poesía puesta en verso -reitera Juan Ramón- no ayuda al lector a comprenderla ni a sentirla. Cuando se escribe un poema, para ver el efecto que produce, para ver si efectivamente es poesía, nada mejor que escribirlo en prosa. En alguna ocasión he traducido al francés, yo mismo, alguno de mis poemas, para comprobar si cierta falla que creía advertir era una falla de la idea o de la forma... La poesía pierde por la arquitectura: por el empeño de darle una forma determinada, una construcción. Así ocurre en Góngora. La música y la poesía no son artes visuales, como algunos parecen creer. Al escribir en prosa un poema, al escribirlo seguido, la poesía gana.

Es evidente que la rima no es el único elemento fónico que diferencia el verso de la prosa, ni que la poesía es un arte exclusivamente oral. Sin embargo, alguna explicación han de tener estas afirmaciones que para Juan Ramón Jiménez parecen 
fundamentales, dada la insistencia con que alude a ellas. Ya se ha señalado en más de una ocasión que resulta extraño que un poeta al que le preocupa la disposición tipográfica y su impresión visual en el lector,

no comprenda la importancia de la relación que se establece entre la superficie escrita y la superficie impoluta de la página; que no aprecie la tensión que ordena significativamente en muchas ocasiones el enfrentamiento de la columna poemática y su contorno (Urrutia, 1981: 720).

Cuando Juan Ramón Jiménez afirma que la poesía no es un arte visual, hemos de creer que no se está refiriendo al hecho de que la poesía tenga que ser percibida exclusivamente por medio de la audición, situación excepcional, sino que la forma externa, su presentación en verso o en prosa, no debe condicionar ni despertar prejuicios tanto en el autor como en el lector. Lo que nos propone es una concepción de la poesía, compartida por el lector y el autor, totalmente liberada de moldes y esquemas ya conformados, una poesía que rompa los horizontes de expectativas formales prefijados en el lector, porque -ya lo hemos citado- «la poesía pierde por la arquitectura: por el empeño de darle una forma determinada, una construcción»; por eso, nos dice en $E l$ trabajo gustoso, «los verdaderos poetas no usan mucho para su concesión comunicativa las formas escritas regulares sino casi siempre, o al menos cuando están en su mejor momento, las formas inventadas». Por tanto, el carácter oral de la poesía, que defiende con tanta insistencia Juan Ramón, empezaría a tener sentido si lo situamos tanto en la órbita del autor en el momento de la creación, como en la del lector-ciego o sin referencias formales - en la descodificación; y, desde esta perspectiva, su planteamiento es coherente con los principios de que parte, sobre todo después de su segunda época, que es cuando manifiesta abiertamente su rechazo a la servidumbre que supone la versificación tradicional.

Luis Cernuda (1970: 188) hace una interesante observación sobre las transformaciones que ha experimentado el verso español. Sobre la rima nos dice que, a partir del Romanticismo, «nos suena demasiado y arrastra demasiado la corriente poética a los escollos del ripio», y que nuestro oído deseaba ya una armonía más sutil que sonora en el ritmo poético. En este punto coincide en parte con el planteamiento juanramoniano de anteponer la oralidad en la percepción de la poesía. Urrutia (1981: 722) refleja perfectamente el desarrollo de su evolución formal — «poética en marcha 
que comienza por la negación del verso rimado y pasa en seguida a la negación de todo verso»-, mediante el siguiente esquema: verso medido y rimado $\rightarrow$ verso libre $\rightarrow$ prosa.

Si el aspecto gráfico no es, como acabamos de ver, distintivo, entonces el verso estaría marcado por la rima o por la medida fija en el caso de los versos blancos, en palabras del poeta (Gullón, 1958: 149):

El verso libre no es realmente verso -dice-; sí lo es el verso blanco, porque tiene medida fija: en español, el endecasílabo. Si la medida no es fija, no es verso. Escrito seguido, el romance mismo gana, pues se lee de una tirada. Cuando leemos poesía lo que se busca es el tope del asonante. El lector parte el romance con el ojo, porque tiene que leer y va hasta el final de cada línea para volver luego al comienzo de la otra. Conviene siempre evitar eso y el latiguillo del recitado.

A propósito de esta reflexión se pregunta Jorge Urrutia (1981: 721) si esto significa que Juan Ramón Jiménez no entendía la función del encabalgamiento. Es evidente que la respuesta es afirmativa; prueba de ello es el uso frecuente que hizo de este recurso, aunque restringido a su primera época y aplicado casi exclusivamente en versos alejandrinos. Sirvan como ejemplo los que siguen: de encabalgamiento léxico o de palabra: «Todos miran / al cielo, abriendo inmensa- / mente los ojos, olvidados / de la tarde», «aquella puerta con jara- / mago en sus ojos ladrillos»; de encabalgamiento sirremático (sustantivo + adjetivo): «Y a la sombra de los chopos / verdes de la carretera»; (verbo + adverbio): «La luna, limpia, albea / oblicuamente la pared»; oracional: «la embalsamada y tibia la paloma azucena / que el profano no entiende, que no entiende al piadoso». Y entre hemistiquios: «Perfumarán las ma-dreselvas cuando vuelvas»; «Yerra la esencia inex-tinguible de lo eterno». Quizá la formulación más adecuada de la pregunta sería cuándo, siguiendo sus pautas, debemos hacer la pausa versal obligatoria, pues es la pausa lo que en definitiva le da valor estilístico al encabalgamiento si no tenemos presente el poema escrito.

De lo dicho por Juan Ramón Jiménez se deduce que sólo existe el verso cuando posee medida fija o está rimado. El verso blanco, al no tener el tope de la rima, es verso porque la regularidad métrica supone conservar la obligatoriedad de la pausa versal. Y en el caso de poemas versolibristas no rimados, cuando se produce desajuste entre la pausa morfosintáctica y la versal (encabalgamiento), ésta no es obligatoria y al no que- 
dar tampoco el recuerdo de la rima, cuya misión, como señala Antonio Quilis (1973: 82), es la de relevar en sus funciones a la pausa versal, no queda ningún elemento que marque fónicamente el final del verso, por lo que es también coherente que Juan Ramón Jiménez opte por transcribir en prosa sus poemas en verso libre sin rima.

Su concepción de la poesía, a veces formulada de manera contradictoria, la desarrolla a partir de la oposición entre poesía (=lo «inefable», abierta) y literatura (=lo «fable», cerrada), y explica, según Antonio Garrido (1991: 336), el sentido dinámico y el perpetuo cambio de su escritura poética:

La oposición anterior es, al mismo tiempo, una declaración de intenciones y una formulación trágica del esfuerzo titánico que el autor tuvo que llevar a cabo en su afán por explorar el misterio de la palabra poética en su autonomía expresiva y en sus valores emocionales, a través del uso de todos los mecanismos que el lenguaje ofrece. La prueba más clara es la reelaboración de lo escrito y el trabajo de prosificación sobre sus poemas realizado en los últimos años.

\section{LAS PROSIFICACIONES DE LEYENDA}

La plasmación de esta idea de coherencia, que nos parece fundamental para el análisis de una obra tan cambiante como la de J.R.J., se manifiesta de una manera inequívoca en el proyecto de Leyenda llevado a cabo por Antonio Sánchez Romeralo, quien completó la ordenación y revisión de la totalidad de la producción poética en verso y prosa, siguiendo las pautas del autor. En el «Prólogo-epílogo» a su edición de Leyenda (1978: XXVI) afirma lo siguiente:

La forma (externa, visual) del poema ha cambiado, en busca de una mayor desnudez. Ahora el verso viene determinado por la rima (el romance, por ejemplo, se escribe en versos de 16 sílabas) y cuando no hay rima no hay verso y el poema se escribe «en prosa». (En esta búsqueda de la desnudez y la sencillez siguen existiendo, creo yo, razones formales, visuales: un hastío de las formas breves, más cantarinas, y, paralelamente, un gusto por los versos largos y las estrofas extendidas, reposadas y nobles. La estrofa poética en prosa adquiere también un valor formal. Hay una equivalencia entre el título largo y el verso largo, la estrofa larga, en la nueva estética de Leyenda.) 
Y en las «Notas a esta edición» (1978: XXXIV) se hace eco de lo dicho por Jiménez al respecto:

La transcripción formal de los poemas ha sido hecha siguiendo los criterios del autor expuestos en un fragmento del prólogo a Leyenda:

"Publico en forma de prosa todo el verso libre sin rima consonante y asonante. La rima es lo único que decide el verso".

Pero a pesar de las manifestaciones explícitas del propio autor, el proceso de prosificación llevado a cabo por Sánchez Romeralo ha sido criticado en alguna ocasión. Antonio Sánchez Trigueros (1991: 315-329) tacha de sorprendente y gratuita la prosificación que de Animal de fondo se hace en Leyenda. Basándose en el análisis métrico de la versión en verso del primer poema, señala que «nos encontramos frente a un poema en verso libre con apoyatura de silva blanca en la serie del endecasílabo, que es el verso predominante, tanto cuantitativamente (15/36) como por su posición». Y centrándose en la estrofa cuarta, observa «en ella una red riquísima de similicadencias, rimas consonantes o asonantes internas, polípotes, sinonimias, paronomasias, juegos tímbricos intensivos e inversiones», de lo que no queda «casi nada en la traducción francesa», y pone «en grave entredicho la prosificación llevada a cabo por Sánchez Romeralo en Leyenda».

Isabel Paraíso de Leal (1971: 253-268 y 1985: 200-206) ya había señalado mucho antes que el verso libre de Juan Ramón procede de la silva modernista arromanzada, estrofa que el poeta usa con bastante frecuencia desde su primera época (1900-1915). «La vitalidad de la silva - añade-, teniendo en cuenta el total de la Obra juanramoniana, supera a la del alejandrino, prueba, pensamos, de que la silva, con su libertad rítmica, es la forma métrica más adecuada para la espontaneidad versificativa juanramoniana». El verso libre lo cultiva Juan Ramón a partir de Diario, y mantiene, según Paraíso, la estructura métrica de la silva, es decir, como un conjunto con predomino de heptasílabos y endecasílabos, y con la diferencia de la ausencia de rima, o con asonancia accidental. «La semejanza entre ambas formas es, pues, muy importante, y nos muestra -concluye Paraíso- que ése es precisamente el "ritmo interior" del poeta». El verso libre, junto con la canción, el romance y el poema en prosa son las formas en que Juan Ramón publica la mayor parte de su poesía. De ellas, el verso libre es la más usada durante esta época, y que terminará, según sus últimas indicaciones, 
convertido en poesía en prosa. Paraíso (1971) cuestiona que el verso libre en Dios deseado y deseante deba considerarse como tal, pues el análisis métrico de los mismos refleja una presencia marcada de los ritmos cuantitativo, acentual y, en menor medida, de timbre. Y a la misma conclusión llega con los poemas transcritos en prosa: «Las "prosas" de Dios deseado y deseante son tan verso en su estructura interior como los “versos", si no más».

Contrastan estas observaciones de Paraíso y Sánchez Trigueros con la opinión que sobre la métrica de Animal de fondo nos da Navarro Tomás (1985: 309): «En realidad, solamente en su último libro, Animal de fondo, donde aparece más concentrado con su misticismo estético, se desentendió de todo elemento de regularidad métrica». Sin embargo Navarro cae en parecido error de apreciación que Predmore ${ }^{1}$ cuando afirma tajantemente que

Su sentimiento rítmico y musical sobrevivió a todo cambio de actitud; en ningún caso se mostró inclinado a prescindir de la canción medida y rimada. Es indudable que para el simbolismo de su poesía ideológica encontró preferible el verso suelto y fluctuante, sin la exigencia de rimas, acentos y medidas, pero es igualmente cierto que para la expresión de sus intuiciones líricas y de su intimidad emocional se acogía invariablemente a los recursos de la palabra rítmicamente organizada. Dentro del esencial lirismo de toda su poesía, el signo más revelador de su inclinación o actitud en cada poema es, acaso, la forma de versificación que adoptó para componerlo.

Si bien es cierto que su sentido rítmico y musical está presente en toda su poesía, tanto en verso como en prosa, también es innegable la evolución que experimenta Juan Ramón en la forma de expresión, perfectamente reflejada en el esquema citado más arriba de Urrutia (1981: 722). Además resulta muy endeble la distinción entre poesía ideológica e intimista, porque ¿qué poema de Juan Ramón no es al mismo tiempo intimista, intuitivo e ideológico? Y por otro lado Navarro Tomás no tiene en cuenta en ningún momento del citado artículo ni las opiniones del propio Jiménez sobre el verso y la prosa ni las prosificaciones.

Diego Martínez Torrón (1981: 801-809), en un artículo en el que analiza las variantes poemáticas de Piedra y cielo que se producen entre las versiones de Segunda

${ }^{1}$ Nos referimos a la distinción, corregida posteriormente, y que hemos reseñado más arriba, entre las composiciones en verso y prosa de Diario. Véase Predmore (1975: 140, n. 2). 
antolojía y Leyenda, llega a la conclusión de que «los poemas que resultan poseen así mayor capacidad de sugerencia, son más sintéticos y escuetos, poseen un ritmo peculiar de prosa poética, y además permiten adivinar el último Juan Ramón panteísta y místico». Veamos qué nos aporta el análisis métrico del último poema de este libro, que aparece en Leyenda bajo el título «Todo verdad presente sin historia», que es, curiosamente, un endecasílabo sáfico:

\footnotetext{
Quisiera que mi libro

fuese, como es el cielo por la noche, odo verdad presente, sin historia.

Que, como él, se diera en cada instante, todo, con todas sus estrellas; $\sin$ que niñez, juventud, vejez quitaran ni pusieran encanto a su hermosura inmensa. ¡Temblor, relumbre, música presentes y totales! ¡Temblor, relumbre, música en la frente -cielo del corazón-del libro puro!
}

Salvo el verso séptimo, que podría dar lugar a 2 heptasílabos, los demás poseen 7 y 11 sílabas -3 de 7 y 7 de 11 , por lo que el poema tiene un marcado ritmo cuantitativo. En cuanto al ritmo acentual, se observa una acentuación predominante en $6^{\mathrm{a}}$ sílaba -10 de $\operatorname{los} 12$ versos-, con apoyos en $2^{\mathrm{a}}, 4^{\mathrm{a}}$ y $10^{\mathrm{a}}$. La asonancia de los versos cuarto y noveno es accidental, y no cabe hablar de ritmo de timbre. Hay un encabalgamiento - sin / que-, muy forzado, entre los versos quinto y sexto que no aporta ningún efecto destacable; la presencia de la preposición «sin» en esa posición parece venir exigida por el cómputo silábico, hecho bastante infrecuente en Juan Ramón. El recitado, respetando las pausas versales, denota algunos desajustes rítmicos injustificados. En general, este poema responde métricamente al esquema de la silva modernista, y confirma lo que decía Isabel Paraíso del ritmo interior del poeta, es decir, el predominio de los metros heptasílabos y endecasílabos.

La versión en prosa es la siguiente: historia. 
Que, como él, se diera del todo en cada instante, con todas sus estrellas, sin que niñez, juventud, vejez quitaran ni pusieran desvelo a su hermosura inmensa.

$Y$ fuera todo traslaticio en su igualdad, todo fugaz sin ser notado, todo jirado en órbitas eternas.

¡Temblor, relumbre, música parciales y totales! ¡Temblor, relumbre, música en la frente (cielo del corazón) del canto sumo!

En el caso concreto de este poema, su versión corregida en prosa, y al margen del acierto de las variantes, supone, en nuestra particular apreciación, una mejoría general al eliminar su forma prosística los problemas rítmicos versales ya apuntados.

En un esquema provisional de Leyenda, organizado por ciclos, que transcribe Sánchez Romeralo en el «Prólogo-Epílogo», Juan Ramón tenía previsto agrupar sus últimos libros en un ciclo que titularía Lírica y Épica de una Atlántida. Estos libros son los escritos en América y conocidos en parte por la Tercera antolojía: En el otro costado, Una colina meridiana, Dios deseado y deseante y Ríos que se van ${ }^{2}$. Esta ordenación cíclica fue suprimida y Leyenda aparece con cuarenta y cinco libros ordenados cronológicamente.

Uno de los casos más significativos de prosificación es el que representa Animal de fondo, escrito en 1948 y publicado un año después en una edición bilingüe en español y francés. Este libro, según su autor, era una anticipación de Dios deseante y deseado, en el que terminó incorporado, pero con el título definitivo de Dios deseado y deseante, publicado en parte por primera vez en 1957 formando parte de Tercera antolojía poética (1898-1953). En esta edición, además de los veintinueve poemas en verso libre de Animal de fondo, se añade un segundo apartado con siete poemas, tres en verso y cuatro en prosa, escritos muy probablemente en 1949. Antonio Sánchez Barbudo publicó en 1964 una nueva edición con el título Dios deseado y deseante (Animal de Fondo) a la que incorpora una tercera parte con veintiún textos nuevos, dos en prosa, la mayoría inéditos, escritos entre 1948 y 1952. También incluye el prólogo inédito «Camino de fe», escrito a finales de 1952 o de 1953, y un interesante anexo con

${ }^{2}$ Este proyecto de Jiménez ha sido materializado en la edición de La lírica de una Atlántida, que reúne, en efecto, los cuatro libros citados (Galaxia Gutenberg-Círculo de Lectores, Barcelona, 1999, edición de A. Alegre Heitzmann). 
el título «Anotaciones, correcciones y versiones diferentes» en el que analiza los originales de los poemas que se han agregado en esta edición.

En Leyenda aparecen prosificados los veintinueve poemas de Animal de fondo con muy ligeras modificaciones, sobre todo signos de puntuación, y el cambio de título del poema 10, que pasa de «Conciencia hoy azul» a «Hoy azul». Sin embargo, en el segundo apartado se observan variaciones más significativas. De los veintiocho poemas (siete + veintiuno) de los dos últimos apartados de la edición de Sánchez Barbudo, se pasa a quince en Leyenda en un único apartado. Hay, asimismo, cambio de título en tres textos, y adición o supresión de palabras o frases en la mayoría.

Según se desprende de los comentarios que hace Sánchez Barbudo en el anexo citado, ante dos o más versiones de un mismo poema, éste prefiere las primeras copias en aquellos casos en que es imposible determinar cuál es la última, y en el caso de que existan versiones en verso y en prosa, elige normalmente la versión en verso. Por el contrario, Sánchez Romeralo opta por lo general por las últimas versiones y en prosa. Un ejemplo lo tenemos en el poema 57, último de la edición de Sánchez Barbudo ${ }^{3}$, del que se conocen tres versiones, todas en verso. La primera, publicada en vida del poeta en la revista Poesía española es la reproducida en esta edición con el título «Si la belleza inmensa me responde o no». La segunda versión coincide casi totalmente con la primera. Y la tercera, posiblemente la última, cambia el título por «Como tú, mi amor, miras», extraído de una estrofa final añadida entre paréntesis. Ésta es la que, prosificada, aparece en Leyenda.

Dios deseado y deseante fue, desde la aparición de Animal de fondo, un libro polémico. Las reiteradas alusiones a Dios y su identificación con el autor han llevado a algunos críticos ${ }^{4}$, o a tachar el libro de irreverente, o a cuestionar su posible carácter religioso, místico o teológico. Quienes así piensan equiparan, erróneamente, el dios «poético» juanramoniano con el Dios «religioso» cristiano, dos entidades distintas concebidas desde ópticas diferentes. El dios de este libro, dice Crespo en el prólogo

${ }^{3}$ Este poema es, según el editor siguiendo lo dicho por Jiménez, el último que compuso, diciembre de 1952, para el libro o, en todo caso, el último de los conocidos.

4 Ángel Crespo nos ofrece un completo resumen de las primeras críticas en el prólogo de su edición de Animal de fondo (1981: 28-42). Antonio Sánchez Romeralo (1985) también comenta en este artículo algunas críticas vertidas sobre el libro. 
citado, «es la culminación de la búsqueda de la actividad por medio de la poesía, de la belleza». Para Antonio Sánchez Romeralo (1985: 169) Animal de fondo es un libro de poesía religiosa, de carácter místico y teológico. El dios, considerado como conciencia general e individual, lo define a través de cuatro caracteres esenciales: dios inmanente, dios-belleza, dios panteísta y dios-amor. Pero es Agustín Caballero (1967: LXII-LXII) quien, creo, mejor ha resuelto esta polémica; y aunque la cita es larga, conviene reproducir sus propias palabras:

Es increíble que hayan podido menudear de tal modo las interpretaciones erróneas sobre un libro que es la transparencia misma, sobre todo si se leen con atención las explicaciones que lo acompañan y si se considera a la luz de la obra precedente. Porque, por encima de todo, Animal de fondo no es sino el desarrollo cartesianamente lógico de ese reducido puñado de temas capitales -belleza, amor, eternidad, autenticidad, pureza, muerte- en que el poeta viene profundizando (ni más nuevo, al ir, ni más lejos; más hondo) desde sus primeros libros; una sublimación -pero sublimación de una congruencia silogística- de toda su poesía. Podrían surgir dudas de interpretación si nos hallásemos ante una vivencia mística, porque la vivencia mística es, en rigor, inexpresable. (...) Pero ¿qué clase de relación mística puede haber, salvo la puramente metafórica, entre el hombre y este dios poético hijo y criatura suya, este dios necesidad y espejo de la conciencia y de la vida humanas, este dios que, en cuanto verbo, solo es participio?

No es, en modo alguno, una mística Animal de fondo: sí, en cambio, una teología, cristalina de concepto y radiante de belleza, acerca del dios deseante y deseado que no es otra cosa sino el yo del poeta gozosamente salvado ya en su obra; el yo que quedará en pie cuando el hombre muera, la voz, por fin, perdurable: el nombre conseguido de las nombres.

Efectivamente, es el propio autor, en las «Notas» que puso como epílogo a este libro, escritas probablemente en 1950, después de concluida su redacción, quien mejor nos explica su concepción mística de la poesía:

Para mí la poesía ha estado siempre íntimamente fundida con toda mi existencia y no ha sido poesía objetiva casi nunca. $Y$ ¿cómo no había de estarlo en lo místico panteísta la forma suprema de lo bello para mí? No que yo haga poesía relijiosa usual; al revés, lo poético lo considero como profundamente relijioso, esa relijión inmanente sin credo absoluto que yo siempre he profesado.

(...) Estos poemas los escribí yo mientras pensaba, ya en estas penúltimas de mi vida, repito, en lo que había yo hecho en este mundo para encontrar un dios posible por la poesía. Y pensé 
entonces que el camino hacia un dios era el mismo que cualquier camino vocativo, el mío de escritor poético, en este caso; que todo mi avance poético en la poesía era avance hacia dios, porque estaba creando un mundo del cual había de ser el fin un dios. Y comprendí que el fin de mi vocación y de mi vida era esta aludida conciencia mejor bella, es decir, jeneral, puesto que para mí todo es o puede ser belleza y poesía, espresión de la belleza.

Animal de fondo es, como ya ha sido señalado en numerosas ocasiones, un libro denso y, en cierta medida, oscuro. Los temas y motivos que lo conforman y su especial cosmovisión tienen en las prosas de Diario y, sobre todo, en «Espacio», sus precedentes más inmediatos. Animal del fondo fue compuesto algunos años antes de la redacción definitiva de «Espacio», por lo que es lógico que existan muchas interconexiones entre ambos textos. El fragmento tercero de «Espacio» se constituye como una prolongación y resolución de algunos de los enigmas poéticos que dejaba en el aire Dios deseado y deseante. Esta última etapa poética de Jiménez, integrada por los títulos que componen Lírica de una Atlántida, debe ser considerada como el corolario de toda una vida en búsqueda permanente de la belleza poética suprema.

La última parte de la Tercera antolojía poética, titulada Ríos que se van, incluye nueve poemas - cuatro en verso y dos en prosa-, escritos entre 1951 y 1953. En Leyenda, y bajo el título De ríos que se van (1951-1954), aparecen veintiocho textos subdivididos en tres apartados: «De ríos que se van: 1», que reproduce los nueve poemas de la Tercera antolojía y añade seis nuevos - cuatro en verso y dos en prosa-; «Orillas que pasamos», con tres poemas en verso; y «De ríos que se van: $2 »$, con diez textos - seis en verso y cuatro en prosa-.

Con la excepción de los poemas de «Orillas que pasamos», anecdóticos, el resto gira en torno a uno de los temas capitales de la poesía de Juan Ramón: la muerte; pero que en el caso de De ríos que se van tiene como referente inmediato la presentida y cercana muerte de Zenobia y él mismo. Para Palau de Nemes (1985: 170), los poemas de este libro son la canción final, a modo de elegía, «del amor desnudo, depurado, a la mujer desnuda, privada de sus bellos atributos físicos por una incurable enfermedad», pero «que transcienden los límites del tiempo y el espacio», y van más allá de sus propias muertes. Sin embargo, la expresión poética tiende inevitablemente a concentrarse en un juego aliterado de referencias pronominales de primera y segunda personas, como puede observarse en «El terrible desvelo» (poema núm. 1294 de Leyenda, pp. 698-699): 
Estás sola de ti misma, sola mía, más de ti que de mí que más te quise que tú quisiste... ¿Y cómo podrá ser que estés tan sola si estuve todo contigo? ¿No quepo en tu soledad? Yo soy más grande por ti que mi vida y que mi muerte; y quepo donde tú estés tan sola en ti misma.

¡No, no me lo puedes decir; eres más grande que yo, eres más grande que el mundo, eres más grande que el cielo, más que la muerte y la nada! ¡Eres ya tu eternidad! ¡No sé qué hacer con lo mío!

\section{CONCLUSIÓN}

Como es sabido, Juan Ramón no concluyó el trabajo de selección, ordenación y corrección de todo el material que compone el libro - sobre todo a partir de Cuadernos y Canción, fue completado por Romeralo «siguiendo siempre cuantas indicaciones pude encontrar, y procurando en todo momento adivinar y conformarme a la voluntad del autor» (ibid.: XXXII)-, por lo que la responsabilidad última de las prosificaciones de las que Jiménez no dejó texto escrito es de Sánchez Romeralo, si bien no se le puede imputar a éste totalmente, pues el propio Jiménez realizó en vida y publicó poemas prosificados que nadie cuestiona. El ejemplo más sobresaliente es, sin duda, el del poema «Espacio», y en el que, curiosamente, el propio Sánchez Romeralo (1985: 150, n. 23) señala la existencia muy frecuente de endecasílabos. Otro caso es el del poema «El desnudo infinito», incluido en Dios deseado y deseante, del que hay dos versiones, una en verso titulada «No quiero exaltación de eternidades», y otra en prosa, posterior y con escasas diferencias, corregida por su autor y con la indicación manuscrita: «Leyenda': 'Dios deseado y deseante' ('Animal de fondo')» (Sánchez Barbudo, 1964: 259). Conviene además recordar al respecto (Aullón de Haro, 1987: 103, n. 47) que «la prosificación de poemas en verso no es algo inusual. En el manuscrito de Hymnen an die Nacht hay poemas en verso que en su versión definitiva aparecieron en prosa. Otro tanto hizo Baudelaire en La Fanfarlo». 
La existencia de ciertas estructuras métricas, con una relativa tendencia a la regularidad, en poemas versolibristas, e incluso en textos escritos originalmente en prosa $^{5}$, no debe extrañar que sea fácilmente detectable en un poeta de las características expresivas de Jiménez. Pero esta constatación no debe servir para descalificar el trabajo llevado a cabo por Romeralo, quien lo único que hace es reflejar en su edición el deseo último de Juan Ramón. Con el resultado final de tales prosificaciones podremos estar en desacuerdo, pero es incuestionable que esa era la intención de Jiménez y forma parte de su poética. Coincidimos con Aullón de Haro (1989: 249-250) en la siguiente observación:

Se comprenderá perfectamente que esta intención no era sino un proyecto de actualización estética de su obra, en especial los libros de la primera época, de los cuales qué duda cabe que el poeta era plenamente consciente, sobre todo a partir de Diario, de la no muy selectiva discriminación ejercida en el día de su publicación y, por otra parte, del envejecimiento que los aquejaba.

Y, por otro lado, la forma prosística, aunque encubra metros convencionales, no es un obstáculo para su consideración como poema en prosa, ni debe invalidar la concepción particular adoptada por Jiménez sobre su poesía.

\section{REFERENCIAS BIBLIOGRÁFICAS}

AlboRnOZ, Aurora de (1982). «Introducción» a Juan Ramón Jiménez, Espacio. Madrid: Editora Nacional, pp. 90-101.

— (1985) (ed.), Juan Ramón Jiménez. Madrid: Taurus (2ª reimp.; 1ª ed., 1981).

Aullón de Haro, Pedro (1987). Los géneros ensayísticos en el siglo XX, tomo 26 de Historia crítica de la literatura hispánica. Madrid: Taurus.

${ }^{5}$ Francisco López Estrada (Métrica española del siglo XX, Madrid, Gredos, 1969, pp. 61 y ss.) analiza los pies métricos de Platero. Arturo del Villar (1985: 239) apunta que lo mismo podría hacerse con Españoles. 
- (1989). La poesía en el siglo XX (hasta 1939), tomo 20 de Historia crítica de la literatura hispánica. Madrid: Taurus.

CABAllero, Agustín (1967). «Juan Ramón desde dentro», prólogo a Juan Ramón Jiménez, Libros de poesía. Madrid: Aguilar (3ª ed.; $1^{\mathrm{a}}$ ed.: 1957), pp. XV-LXIX.

CERnUdA, Luis (1970). Crítica, ensayos y evocaciones (Edición, prólogo y notas de Luis Maristany). Barcelona: Seix Barral.

CRESPO, Ángel (1981). «Prólogo» y «Nota bibliográfica» a Juan Ramón Jiménez, Animal de fondo (con la versión francesa de Lysandro Z.D. Galtier). Madrid: Taurus, pp. 9-56 y 57-59.

Cuevas García, Cristóbal (1991) (dir.) y Enrique BAENA (coord.). Juan Ramón Jiménez. Poesía total y obra en marcha (Actas del IV Congreso de Literatura Española Contemporánea, Málaga, 1990). Barcelona: Anthropos-Servicio de Publicaciones e Intercambio Científico de la Universidad de Málaga.

DíAZ-Plaja, Guillermo (1956). El poema en prosa en España. Estudio crítico y antología, Barcelona: Editorial Gustavo Gili.

GARRIDO, Antonio (1991). «Matización a un concepto teórico literario de Juan Ramón Jiménez», en Cristóbal Cuevas García (dir.). Barcelona: Anthropos, pp. 331343.

Gullón, Ricardo (1958), Conversaciones con Juan Ramón Jiménez, Madrid, Taurus.

MARTínez TORRón, Diego (1981). «Variantes poemáticas de "Piedra y cielo": de la Segunda antolojía a Leyenda». Cuadernos hispanoamericanos, núm. 376-378, pp. 800-809.

NAVARRo TOMÁs, Tomás (1985). «Juan Ramón Jiménez y la lírica tradicional», en Aurora de AlBORNOZ (ed.), pp. 307-324. [Antes en La Torre, año, XVI, núm. 59 (enero-marzo de 1988).]

PALAU DE NemES, Graciela (1959). «Prosa prosaica y prosa poética en la obra de Juan Ramón Jiménez», PMLA (Publications of the Modern Language Association of America), núm. 1, vol LXXIV, pp. 153-156.

— (1985), «La elegía desnuda de Juan Ramón Jiménez: "Ríos que se van”», en Aurora de Albornoz (ed.), pp. 170-176. [Antes en Papeles de Son Armadans, año XIII, Tomo L, núm. CXLIX (agosto de 1968).] 
PARAÍso DE LEAL, Isabel (1971). «El verso libre de Juan Ramón Jiménez en Dios deseado y deseante», Revista de Filología Española, LIV, pp. 253-269.

Predmore, Michael P. (1975). La obra en prosa de Juan Ramón Jiménez. Madrid: Gredos ( $2^{\mathrm{a}}$ ed. ampliada).

QuiLis, Antonio (1973). Métrica española. Madrid: Alcalá (2ª ed.; $1^{\mathrm{a}}$ ed.; 1969).

SÁNCHEZ BARBUdo, Antonio (1964). «Introducción» a Juan Ramón Jiménez, Dios deseado y deseante (Animal de fondo). Madrid: Aguilar, pp. 19-44.

SÁnchez Romeralo, Antonio (1978). «Prólogo-epílogo» a Juan Ramón Jiménez, Leyenda (1896-1956). Madrid: Cupsa, pp. IX-XXXIV.

— (1985), «Juan Ramón Jiménez en su fondo de aire», en Aurora de AlbornOz (ed.), pp. 146-169. [Antes en Revista Hispánica Moderna, Nueva York, vol. 27, 1961, pp. 299-319.]

SÁnChez Trigueros, Antonio (1991). «Noticia sobre una investigación de Animal de fondo», en Cristóbal CuEvas García (dir.), pp. 315-330.

URRUTIA, Jorge (1981). «Sobre la práctica prosística de Juan Ramón Jiménez y sobre el género de Platero y yo», Cuadernos hispanoamericanos, núm. 376-378, pp. 716730.

VILlAR, Arturo del (1985). «Juan Ramón Jiménez, crítico literario», en Aurora de AlBORNOZ (ed.), pp. 232-241. [Antes en La estafeta literaria, núm. 562, Madrid, abril de 1975, pp. 4-7.] 